\title{
UNITED WE STAND, DIVIDED WE FALL: PODER DE CLASE, CADENAS GLOBALES DE VALOR Y ESTRATEGIAS SINDICALES EN EL PARQUE DE PROVEEDORES DE MERCEDES-BENZ VITORIA-GASTEIZ*
}

\author{
Jon Las Heras \\ Universidad de Manchester - Global Political Economy
}

\section{ABSTRACT}

Resumen: La globalización del capitalismo en su forma neoliberal ha puesto bajo presión los derechos de los trabajadores y las organizaciones de clase. Este artículo presenta una experiencia positiva para cuestionar la idea de que la lucha de clases es estéril, en vez de limitada, contradictoria o desigual. Para ello, el artículo presenta inicialmente un esquema teórico donde el poder de clase $y$ estrategias de clase están integradas dialécticamente y en continua transformación. El artículo pasa a revisar la literatura de Economía Politica Global para entender la formación de las Cadenas Globales de Valor. Una aproximación metodológica cualitativa que enfatiza la importancia de las entrevistas en profundidad para entender la cosmo-visión de los agentes sociales precede al estudio de caso. El resto del artículo estudia las estrategias sindicales en la planta de automoción de Mercedes-Benz Vitoria-Gasteiz y, primordialmente, la de los proveedores y subcontratas. La estrategia beligerante e inclusiva

* Comunicación presentada en el en el II Encuentro de Profesionales del Asesoramiento Laboral y Social, celebrado en la Facultad de Relaciones Laborales y Trabajo Social (UPV/EHU-Leioa) el dia 30 de septiembre de 2016. 
de ELA fue crucial durante los 2000 para la transformación positiva de su poder económico $e$ ideológico en un contexto adverso. Los márgenes para la lucha existen, el problema es encontrarlos y actuar.

Palabras clave: poder y estrategias de clase, globalización, Cadenas Globales de Valor, sindicalismo, renovación sindical

Abstract: The globalization of capitalism in its neoliberal form has put under increasing pressure workers' rights and class organisations. This article presents a positive experience in order to challenge the idea that class struggle is unfruitful, rather than limited, contradictory and uneven. To do so, the article first advances a theoretical framework in which class power and class strategies are dialectically integrated and understood as continuously transforming. After, the article reviews the Global Political Economy literature that helps us to understand the formation of Global Value Chains. A qualitative methodological approach that stresses the importance of interviews in understanding world-views is presented. The rest of the article focuses on a case study on trade union strategies in the automotive factory of Mercedes-Benz Vitoria-Gasteiz and its subcontractors/suppliers. ELA's oppositional and inclusive trade union action was paramount during the 2000s for the positive transformation of their economic and ideological power in a context in which they had everything against. Margins for struggle exist, the problem is to find them and engage with them.

Keywords: class power and strategies, globalisation, Global Value Chains, Trade Unions, union revitalization

Laburpena: Kapitalismo neoliberalaren globalizazioak presioan jarri ditu langileen eskubideak eta klase organizazioak. Artikulu honek esperientzia positiboa aurkezten $d u$, zalantzan jartzeko klase borroka ideia antzua dela, murriztua, kontradiktorioa edo ezberdina baino. Hori egiteko, artikuluak eskema teoriko bat aurkezten du non klase botere eta klase estrategiak mugimendu dialektikoan barneraturik eta etengabeko eraldatze-prozesuan dauden. Artikuluak, Ekonomia Politika Globalaren literaturan oinarrituz, Balorezko Kate Globalen garapena aurkezten du; ondoren, metodologia kualitatiboaren balioa mundo-ikuspuntuak elkarrizketen bidez ikertzeko azaltzen da. Artikuluaren gainontzekoa Mercedes-Benz Vitoria-Gasteizko automobil faktorian eta, batez ere, azpikontratetan eta hornitzaileetan izan diren estrategia sindikalak ikertzen ditut. ELAk 2000-2010 hamarkadan, testuinguru gogorrean, izan dituen borroka eta estrategia integratzaileak positiboak izan dira langileen botere ekonomiko eta ideologikoa handitzeko. Borroka egiteko marjinak badira, arazoa da horiek aztertu eta jardutea.

Hitz gakoak: klase botere eta estrategiak, globalizazioa, Balio Kate Globalak, sindikalgintza, berrikuntza sindikala 


\section{SUMARIO}

Sumario: 1. Introducción. 2. Poder de clase y Cadenas Globales de Valor. 2.1. Una aproximación dialéctica al poder y estrategias de clase. 2.2. Sobre cómo los trabajadores han perdido su poder durante los últimos treinta años. 3. Preguntas y método de investigación. 4. Cómo la acción sindical de ELA empoderó a los trabajadores del parque de proveedores y subcontratas. 4.1. Los «Pactos de Competitividad» en Mercedes-Benz Vitoria-Gasteiz. 4.2. Los proveedores y subcontratas siguen su propio camino: ELA empodera a los trabajadores y mejora sus condiciones laborales. 5. Conclusión. 6. Entrevistas. 7. Hemeroteca. 8. Bibliografía.

\section{Introducción ${ }^{1}$}

Ante las sempiternas presiones del capital y su estrategia de «divide y vencerás», ejemplificadas en el desarrollo de las Cadenas Globales de Valor, el famoso grito de lucha «united we stand, divided we fall» (juntos permaneceremos, divididos caeremos) gana sentido dentro del mundo obrero. La progresiva liberalización de los mercados laborales y la desarticulación de las estructuras de negociación colectiva, así como la negociación a la baja de las condiciones salariales y laborales a través de la firma de «pactos de competitividad", ponen de manifiesto el progresivo desempoderamiento de los trabajadores a lo largo del mundo.

Debido a que la lucha entre capital y trabajo no está preestablecida ni es homogénea, la necesidad de construir un esquema teórico que nos permita entender las limitaciones, posibilidades y contradicciones de la acción colectiva/sindical de los trabajadores recobra su fuerza. La lógica imperante en los países occidentales es la de satisfacer las demandas empresariales debido a una creciente competitividad en los mercados internacionales. Mientras, los enfoques Marxistas, críticos o beligerantes con el status-quo quedan marginados. Poder interpretar las experiencias positivas dentro del mundo sindical de forma crítica se nos hace imprescindible para poder aprender de ellas y poder

1 Agradezco a Lluis Rodríguez e Iker Urkiola por sus acertadas críticas y sugerencias a anteriores borradores. Posibles errores u omisiones son responsabilidad del autor. 
trasladarlas a otros contextos, enriqueciendo y fortaleciendo no sólo las experiencias de lucha sino también los enfoques teóricos que enfatizan la necesidad de las mismas.

El presente artículo contribuye a tal programa de investigación, desarrollando un enfoque Marxista a la interacción entre estructura y agencia, poder y estrategias de clase (Sección 2.), para presentar un estudio de caso, esta vez positivo, sobre las estrategias sindicales dentro de la factoría de Mercedes-Benz Vitoria-Gasteiz (Sección 3). El caso de estudio sintetiza el trabajo de campo realizado por el autor entre febrero y abril de 2015. La Sección 3 presenta, de manera resumida, una parte de las entrevistas semi-estructuradas a los representantes sindicales de los diferentes sindicatos en la fábrica. Más concretamente, la mayoría absoluta que ELA poseía en los comités de empresa de varias empresas proveedoras y subcontratas en la fábrica, pone de manifiesto que la coordinación y oposición ante las demandas del capital puede mejorar las condiciones salariales y laborales de los trabajadores. De tal forma, y dentro de las limitaciones que suponen las actuales dinámicas de acumulación capitalistas, las experiencias de ELA en Mercedes-Benz Vitoria-Gasteiz pueden servirnos como ejemplo para pensar que, incluso el más pequeño puede cambiar su poder y posición en la estructura social.

\section{Poder de clase y Cadenas Globales de Valor}

\subsection{Una aproximación dialéctica al poder y estrategias de clase}

Partiendo de una conceptualización holística/sistémica hacia la posición estratégica que toman los actores sociales/sindicales en la lucha de clases globalizada, podemos analizar las diferentes estrategias y acción social/sindicales en su contexto histórico. Esto, nos permite entender las posibilidades, limitaciones y contradicciones de las mismas (véase Jessop, 2008; Hyman, 1975; 1989; 2007; Gumbrell-McCormick y Hyman, 2013). En una primera aproximación simplificada, podríamos conceptualizar el poder y estrategias de clase dentro de las sociedades capitalistas en los siguientes términos:

A. El poder de los actores sociales/sindicales para desarrollar y materializar un conjunto de estrategias de clase está determinado históricamente por su posición estructural dentro de las dinámicas de acumulación de capital (economía), de la intervención legal sobre la sociedad (política), y la creación, liderazgo y organización de las estrategias de clase (ideología);

B. Las estrategias de clase de los actores sociales/sindicales están, a su vez, articuladas con el objetivo de reproducir, reformar/mejorar o transformar dichas estructuras económicas, políticas e ideológicas. 
Las estructuras de poder y estrategias de clase se entrelazan de forma dinámica e indeterminada, ya que ninguna estructura es omnipotente y está ausente de contradicciones, y ninguna estrategia es coherente y capaz de embarcar la totalidad de las estructuras (Jessop, 2008: 40-44). Esta aproximación al poder de clase nos invita a contextualizar el "campo estratégico» de forma precisa para que las estrategias de clase (o sindicales) ganen sentido histórico y nos sirvan para entender la efectividad de las mismas, así como las contradicciones que generan en su interacción con las estructuras.

Desarrollando un enfoque más concreto y complejo desde una perspectiva Gramsciana-Regulacionista, la dialéctica entre la estructura y la agencia puede plantearse de la siguiente forma ${ }^{2}$. Por una parte, el poder de clase está constituido por la posición relativa que los actores sociales tienen dentro de:

A. Las relaciones económicas, i.e. la posición/función de los trabajadores dentro de la economía capitalista y el proceso de acumulación que está formado por: (I) el poder negociacional dentro del mercado de trabajo (posesión de habilidades, tasas de empleo/desempleo en el ámbito geográfico relevante, capacidad de reproducir la fuerza de trabajo sin entrar en el mercado laboral a través de riqueza ahorrada/heredada o políticas fiscales redistributivas); (II) poder negociacional en el lugar de trabajo (autonomía o capacidad para controlar, organizar, diseñar o interrumpir el proceso de trabajo y la producción de mercancías); (III) poder como consumidor (capacidad de boicotear o interrumpir la venta de mercancías y realización del valor producido en la economía).

B. Las relaciones políticas, i.e. la posición/función de los trabajadores dentro del sistema jurídico-legal y ejecutivo que pertenece exclusivamente a la "sociedad política» o al "estado capitalista»: (I) poder para legislar o promover una serie de leyes que conciernen al fisco, políticas monetarias, al mercado de trabajo o a la estructura de la negociación colectiva (e.g. capacidad para implantar leyes o políticas públicas que mejoren las condiciones económicas y sociales de la población; reformar o transformar la estructura que regula las relaciones laborales, etc.); (II) poder de negociación colectiva dentro de las estructuras bipartitas o tripartitas (e.g. capacidad de establecer acuerdos interconfederales; capacidad de nego-

2 El siguiente esquema fusiona tres literaturas en un sistema único para analizar la diálectica de la estructura y agencia desde una perspectiva de clase. Por una parte está la literatura GramscianaRegulacionista en el análisis de economía política (Jessop, 1990: 2008), por otra la literatura sobre relaciones laborales desde una perspectiva Marxista (Hyman, 1975: 1989), y por última la literatura sobre poder y revitalización sindical que enfatiza los dilemas ante los cuales las organizaciones sindicales se enfrentan hoy día (Silver, 2003; Levesque y Murray, 2010; Kelly, 1998; Gumbrell-McCormick, y Hyman, 2013). 
ciar en un convenio sectorial provincial habiendo pasado el $15 \%$ de representatividad mínima en las elecciones sindicales, etc.).

C. Las relaciones ideológicas, i.e. la posición/función de los trabajadores dentro de la producción, articulación, organización y proyección de una serie de estrategias/discursos que guían a los actores sociales en la sociedad civil: (I) poder de los trabajadores (o representantes sindicales) para producir persuasivamente una identidad-conciencia de clase que les proporcione una serie de esquemas mentales o discursos para dar sentido a la realidad social y les guíe en su acción colectiva; (II) poder de los trabajadores (o representantes sindicales) para asociarse con otros trabajadores bajo una identidad-conciencia colectiva que exprese sus intereses de clase; (III) poder de los trabajadores (o representantes sindicales) para organizar y articular los intereses colectivos bajo un marco institucional, a la vez que les provee de los recursos materiales-financieros necesarios para realizarlos (e.g. constituir organizaciones obreras como sindicatos, asambleas de parados, asambleas como la Plataforma de Afectados por la Hipoteca, etc.); (IV) poder de los trabajadores (o representantes sindicales) para forjar alianzas con otros colectivos, organizaciones o movimientos sociales que compartan intereses o estrategias similares aunque, también, difieran en identidad, afiliación y agenda; $(\mathrm{V})$ poder de los trabajadores (o representantes sindicales) para aprender, reflexionar y enmarcar los problemas sociales y estrategias de forma efectiva, mientras que usan sus recursos de forma inteligente.

Este esquema teórico, a la vez que teoriza el poder de clase desde una perspectiva holística nos proporciona los mecanismos para analizar los conflictos y dinámicas en diferentes niveles de abstracción y escalas geográficas: desde los conflictos laborales y sociales a escala nacional o internacional, hasta las luchas sindicales en el mismo centro de trabajo. El esquema propuesto sitúa al trabajador (organizado) en el punto de mira y, dependiendo del contexto y problemática que se quiera estudiar, se dará mayor importancia a un conjunto de relaciones de poder y acciones estratégicas sobre otras. Fuera de cualquier marco histórico, la acción individual o colectiva de los trabajadores pierde significado e interés, pudiendo fácilmente caer en análisis que quitan u otorgan un peso desproporcionado al poder y estrategias de clase.

De la misma forma, las acciones estratégicas de clase se entenderán como las acciones individuales o colectivas que producen o generan el poder de clase: la articulación de acciones que, en base a una reflexión más o menos completa del contexto por parte de los agentes sociales, cambiarán en mayor o menor grado, en una u otra dirección, las estructuras donde se encuentran. Por lo tanto, la acción estratégica reproducirá, reformará o transformará las estructuras de poder sin saber a ciencia cierta cuál será el resultado de la interlocución con el entorno, 
generando nuevas estructuras de poder con sus propias contradicciones debido a la naturaleza limitada de la acción individual o colectiva en sociedad.

En particular, en este periodo histórico en el que el capital domina ampliamente al trabajo (véase Sección 2.2.), nos encontramos con el dilema entre desarrollar una estrategia economicista que adopta la lógica mercantil para asegurar la "competitividad» y beneficios empresariales como intercambio de un empleo cada vez más precario (i.e. corporativismo a la antigua usanza), o adoptar una estrategia de oposición ante las demandas empresariales con el fin de, y desde una perspectiva radical que sobrepone la reproducción de las condiciones de vida de los trabajadores a la necesidad imperativa de las empresas de aumentar su beneficio económica, mejorar o subvertir la situación de subordinación en la que se encuentran. La segunda estrategia, por definición, tiende a generar situaciones más disruptivas e imprevistas que la anterior ya que cuestiona el status-quo y pone sobre la mesa las contradicciones del mismo con el fin de superarlas. Ambas estrategias, en cualquier caso, no tendrán que entenderse como binarias, y a pesar de que en una infinidad de momentos pueda llegar a dividir la adopción de una u otra estrategia a diferentes grupos de trabajadores en su lucha con el capital. Distintamente, las estrategias pueden entenderse dentro de una demarcación continua, entendiéndose por una posición de antagonismo mayor sólo en relación a lo que contextualmente viene practicándose como corporativismo o «diálogo social». Esta aproximación relativista nos permite situar y estudiar acciones más o menos transgresoras en un contexto de subordinación generalizada.

La aproximación dialéctica al poder y estrategias de clase que acabamos de presentar, nos permite entender, por una parte, la necesidad de algunas acciones dentro de un contexto histórico, como por ejemplo: que los trabajadores tengan que negociar sus condiciones laborales dentro de las Cadenas Globales de Valor a pesar de que puedan adoptar planteamientos políticos completamente rupturistas debido a su posición subordinada en la sociedad; por la otra, nos permite entender la contingencia de las estructuras, como por ejemplo: que ante una negociación colectiva donde esté en riesgo el futuro de la planta, algunos trabajadores decidan ir más allá desafiando los planteamientos empresariales y movilicen al resto de la plantilla para defender sus intereses de clase aun poniendo en riesgo sus empleos. Es decir, este enfoque teórico nos abre las puertas para analizar la reproducción, reforma o transformación de las estructuras de poder como resultado de la acción estratégica de los agentes sociales en un contexto histórico determinado.

\subsection{Sobre cómo los trabajadores han perdido su poder durante los últimos treinta años}

Después de la Segunda Guerra Mundial la mayor parte de los países occidentales regularon sus economías (nacionales) capitalistas a través de un conjunto de instituciones o pilares que formaban lo que comúnmente ha sido denominado 
como Fordismo o la «edad de oro» ${ }^{3}$. El crecimiento económico, el pleno empleo, y mayor redistribución de la riqueza fueron posibles debido al conjunto de instituciones políticas que atenuaron las contradicciones de una economía capitalista, permitiendo que existiera provisionalmente la «paz social» entre clases (Kotz et al. 1994; O’Hara, 2006). La crisis de los ochenta y la posterior desindustrialización y globalización del proceso productivo pusieron de manifiesto las dificultades que un empoderamiento de la clase trabajadora suponía para el control económico y político de la clase capitalista (véase por ejemplo Kalecki, 1943).

La Globalización puede entenderse pues como la respuesta de las diferentes clases sociales ante las contradicciones de dicho periodo, dando pie a nuevas formas de lucha entre capital y trabajo (McDonough et al. 2010). El resultado, hasta día de hoy, ha sido una progresiva transformación y ampliación de las relaciones de producción capitalistas a escala mundial para sobreponerse a los límites y contradicciones que las instituciones nacionales reproducían (Brenner, 2004). Más concretamente, referentes académicos dentro de la economía política radical han denunciado una mayor subordinación, fragmentación y desregulación de los trabajadores en el mercado laboral y tejido productivo a través de la formación de Cadenas Globales de Valor (Moody, 1997; Harvey, 2014); la creciente financiarización de la economía que resulta de las dinámicas de sobreacumulación capitalistas (Kotz, 2013); la erosión, aunque diferenciada, de los Estados de Bienestar a lo largo de todos los países capitalistas occidentales (Jessop, 2013; 2016; Buendía y Las Heras, 2014); y la subordinación ideológica de las instituciones públicas y organizaciones de la clase, i.e. sindicatos, a las demandas del capital (Urban, 2012). Por lo tanto, y a pesar del carácter diferencial de la lucha de clases en diferentes contextos o matrices espacio-temporales, podemos entender los últimos treinta ańos como un proceso continuo donde los trabajadores han perdido su poder como clase en sus diferentes dimensiones, i.e. económica, política e ideológica. La pregunta subyacente ante este problema es: ¿Cómo revertir o transformar la actual situación de subordinación creciente y generalizada? Para poder encontrar posibles respuestas debemos, sin embargo, contextualizar más la problemática para poder así articular una serie de estrategias que nos ayuden a dar pasos hacia delante de manera efectiva.

La constitución y evolución de las Cadenas Globales de Valor (CGV) a partir de 1980 son un claro ejemplo de dicho proceso de Globalización y desempo-

\footnotetext{
${ }^{3}$ Las instituciones más importantes vendrían a ser: el tratado de Bretton Woods que establecía ciertos límites a los mercados internacionales y transferencias de capitales; políticas fiscales y redistributivas de corte Keynesiano que dieron paso al nacimiento de los Estados de Bienestar; la estructuración del proceso productivo bajo técnicas Tayloristas en grandes fábricas; el predominio del capital industrial sobre el financiero y mercantil; una estructuración de la negociación colectiva que daba peso a las organizaciones sindicales de clase, y especialmente industriales, debido a su creciente control sobre el proceso productivo en las grandes fábricas Fordistas (véase Boyer, 1990; Jessop, 1990).
} 
deramiento de la clase trabajadora. Según Contractor et al. (2010), la implantación de las CGV sigue una lógica empresarial de:

(I) Dividir la cadena de valor en el mayor número de secciones/partes que puedan ser económicamente y organizacionalmente rentables (producción ligera);

(II) Decidir cómo deben las diferentes secciones/partes estar organizadas (externalización) y geográficamente localizadas (deslocalización).

La estructura productiva Fordista, donde una gran parte de los procesos económicos se realizaban dentro de la "empresa integral», ha dado paso a una nueva estructura de organización y gobernanza económica donde las empresas se centran fundamentalmente en mantener aquellas actividades económicas donde puedan generar/producir mercancías de mayor valor ańadido. Estudios empíricos muestran cómo la estructura empresarial no sigue una pauta puramente capilar, sino que existen diferentes "colaboraciones estratégicas» empresariales que concentran el poder económico de manera desigual a lo largo de la cadena de valor (Sturgeon et al. 2008; Gereffi, 2014; véase Diagrama 1 como un esquema simplificado de la industria automotriz). En su conjunto, las CGV no sólo implican mayores volúmenes de Inversión Directa Extranjera y comercio internacional, sino una «descentralización [del proceso productivo] y una centralización de las decisiones estratégicas [corporativas]» (Constructor et al. 2010: 1420; para una revisión de la literatura véase Gereffi, 2014). El fin último de dichas estrategias es el aprovechamiento y explotación sistemática de los diferentes costes, condiciones y regulaciones laborales de diversas geografías, sectores económicos y lugares de trabajo para aumentar el beneficio empresarial (Caprile, 2000).

\section{Diagrama 1}

\section{Cadena de Valor y Estructura de Poder en Automoción.}

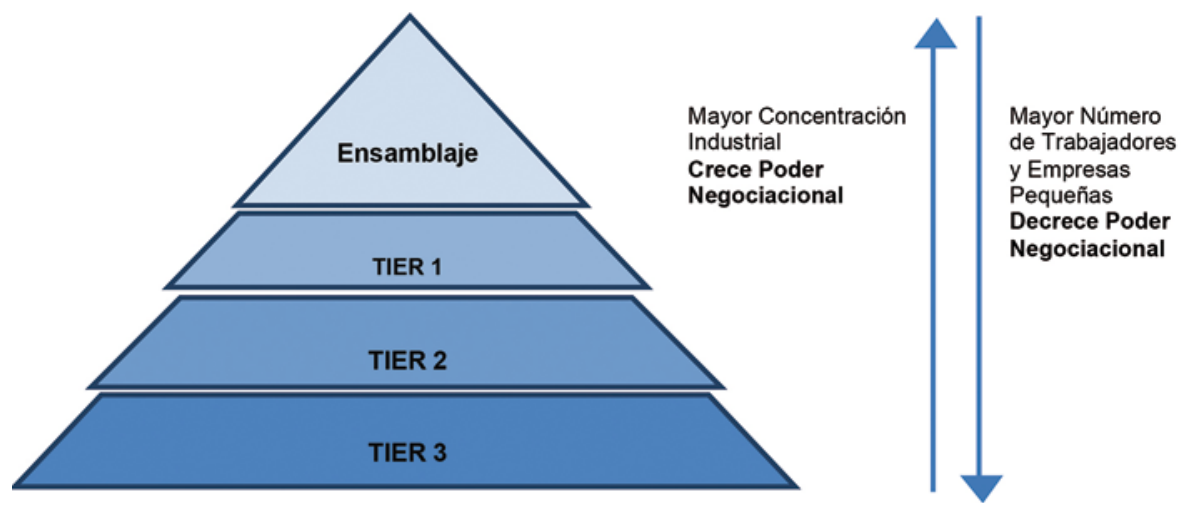

Fuente: Las Heras (2015:98) 
En el Estado Español las GGV en la industria automotriz nacieron a partir de los años ochenta con la fragmentación de la cadena de valor Fordista, y se consolidaron a lo largo de los años noventa con la introducción de técnicas de producción ligera, Just-in-Time y Just-in-Sequence (Peligros y Bilbao-Ubillos, 2005; Ortiz-Villajos, 2010). Dentro de las CGV europeas, las factorías en el territorio Español tienen una posición subordinada debido a una relativa especialización en vehículos y componentes de menor/medio valor añadido (Gracia y Paz, 2014). Esto las pone en una situación difícil ante una creciente competición internacional que incrementa las posibilidades de cierre o deslocalización (Alaez y Barneto-Carmona, 2008; Alaez et al. 2009) ${ }^{4}$ o, como la crisis ha evidenciado, ante una caída sostenida de la demanda efectiva (Boundi y Flores, $2014)^{5}$.

Desde una perspectiva de economía politica radical, donde los conflictos entre capital y trabajo adquieren un carácter estructural a la vez que dinámico y abierto, las CGV pueden teorizarse como el espacio donde las estrategias y luchas de clase se manifiestan a través del tejido productivo industrial global desde los ańos noventa (Sylver, 2003; Dunn, 2004; Cumbers et al. 2008; Selwyn, 2012). El incremento de competitividad entre diferentes factorías por las inversiones de capital fijo, gestionadas éstas por las direcciones de las multinacionales a nivel internacional, han generado dinámicas micro-corporatistas entre trabajadores y representantes sindicales, desempoderando a la clase trabajadora en el plano ideológico, además del económico y político, debido a una adopción del discurso empresarial (Rehmann, 2013). Más concretamente, a través de «pactos de competitividad" los sindicatos en los diferentes países de Europa occidental han otorgado bajadas salariales o peores condiciones laborales (e.g. mayor flexibilidad funcional u horaria) a las empresas bajo la justificación de que es la única estrategia posible que pueda asegurar la "competitividad» de la factoría, la asignación de inversiones de capital fijo y el empleo de los trabajadores ( $\mathrm{Za}$ gelmeyer, 2001; Erne, 2008). Esto, obviamente, ha tenido repercusiones negativas sobre el poder en el mercado laboral de los trabajadores y la economía global. Una reducción de la demanda efectiva incrementa aún más las dinámicas de sobre-acumulación que existen desde los años ochenta y que, debido a una sobrecapacidad productiva, reduce a su vez el beneficio empresarial, empujando a que las empresas generen mayores tasas de explotación para mantener su rentabilidad a costa de una mayor desigualdad económica y mayores tasas de desempleo (Kalecki, 1954; Schulten, 2013; Las Heras, 2015). Las diferentes estrategias sindicales que han intentado empoderar a los trabajadores a lo largo de la misma

\footnotetext{
${ }^{4}$ En cambio, en la CAPV, debido a su tejido industrial con mayores ratios de I+D, productividad laboral, y mayor ratio de capital/trabajo, el riesgo de cierre de factorías es relativamente menor al resto del estado (véase Bilbao-Ubillos, 2010).

5 Entre 2008 y 2013 se ha destruido casi un tercio del empleo en el sector.
} 
CGV, así como entre diferentes CGV que compiten dentro y entre las empresas multinacionales son hasta la fecha limitadas ${ }^{6}$. Bajo el marco de Relaciones Laborales que regula la industria automotriz en el territorio Espańol (Navarro-Nieto, 2009; Valdés-Dal-Ré, 2012), estas dinámicas han generado un mayor desempoderamiento de los trabajadores, tanto a nivel económico como ideológico, a medida que tienen una posición estructural más desventajosa dentro de la propia CGV (Castillo y Lopez-Calle, 2003; Recio et al. 2008; Banyuls y Lorente2010; véase Diagrama 1). Es decir, existe una alta correlación entre la posición que ocupa la empresa dentro de la CGV y las condiciones laborales y salariales que tienen los trabajadores, limitando el «efecto paraguas» que los convenios de ámbito superior pudieran tener dentro de la estructura de la negociación colectiva ${ }^{7}$.

\section{Preguntas y Método de Investigación}

Al contrario de una posición epistemológica positivista que plantea una serie de hipótesis para refutar o corroborar una teoría, una aproximación crítica a las ciencias sociales asume la imposibilidad de descubrir la verdad en un sentido absoluto o trans-histórico. Al contrario, y desde una perspectiva historicista, la teoría social crítica se limita a generar un conjunto de proposiciones dentro de un esquema teórico coherente que nos informe de cómo se estructura y evoluciona la realidad en un contexto determinado (Marsh y Stoker, 2002; Sayer, 2010). Así, más que establecer un conjunto de hipótesis a refutar ad hoc, la teoría crítica prefiere avanzar una serie de preguntas que nos ayudan a entender y explicar la sociedad desde una perspectiva particular, estudiar la coherencia de la teoría en base a la realidad estudiada, y producir una serie de proposiciones que nos permitan intervenir en ella.

Siguiendo la línea argumentativa de la Sección 2 la pregunta de investigación principal que el artículo plantea puede entenderse como:

«¿Cómo han incidido las diferentes estrategias sindicales a la hora de reproducir, reformar o transformar su poder como clase dentro de la CGV de Mercedes-Benz Vitoria-Gasteiz?»

6 Con respecto a las estrategias sindicales a nivel transnacional véase por ejemplo: Waddington (2011), Antentas (2015). Con respecto a las estrategias sindicales para re-organizar a los trabajadores a lo largo de la cadena de valor véase Pulignano et al. (2008), Selwyn (2012).

7 Sin que existan motivos económicos aparentes, e.g. mayor habilidad y destreza, varios estudios sugieren una diferencia salarial de entre por lo menos $25-35 \%$ entre los trabajadores de las plantas de ensamblaje y los del TIER1, TIER2 o TIER3. Los primeros suelen tener reguladas sus condiciones laborales primordialmente a través de convenios de empresa. Luego, a medida que bajan en la escala la regulación se limita mayormente a pactos de empresa o convenios colectivos provinciales del metal, sino otros convenios colectivos con menor poder adquisitivo (Alaez et al. 2009; Banyuls y Lorente, 2010). 
El método de investigación utilizado sigue una lógica cualitativa, i.e. realizar una serie de entrevistas semi-estructuradas a actores relevantes, análisis de documentos producidos por los diferentes actores sociales sobre el contexto estudiado, y análisis de noticias de periódicos locales que nos informan de los detalles que las entrevistas no han podido recoger (Devine, 2002; Brinkmann y Kvale, 2009). Principalmente, a través de las entrevistas en profundidad uno puede:

Explorar las experiencias subjetivas de las personas y los significados que les dan a dichas experiencias. Realizar entrevistas de forma intensiva, por ejemplo, permite a las personas hablar con libertad y dar su opinión e interpretación de los hechos. En la entrevista es su perspectiva lo más importante. [...] Haciendo hincapié sobre contextos específicos, y situando las actitudes de los entrevistados en los mismos, es posible generar una biografía individual y del contexto. [...] Los métodos cualitativos son buenos a la hora de capturar significados, procesos y contextos. Esto es a veces referido como una aproximación holística [a las ciencias sociales] (Fiona, 2002).

El trabajado de campo para este estudio de caso consiste en un conjunto de entrevistas (más de treinta) que fueron realizadas a trabajadores y representantes sindicales de varios sindicatos (ELA, LAB, CCOO, UGT) en Mercedes-Benz Vitoria-Gasteiz entre finales de Febrero y Abril de $2015^{8}$. Debido al dominio que los representantes del sindicato ELA han obtenido en los diferentes comités de empresa de las compañías TIER1 situadas en el parque de proveedores, el artículo se centrará primordialmente en aquellos para analizar en mayor profundidad las estrategias desarrolladas por dicha organización.

\section{Cómo la acción sindical de ELA empoderó a los trabajadores del parque de proveedores y subcontratas}

La fábrica de Mercedes-Benz Vitoria-Gasteiz (MBV) producía su primera Vito en 1995 a la vez que consolidaba su estructura productiva como una CGV, expandiendo sus mercados al resto de Europa, Asia y América (Auñamendi Entziklopedia, 2008; véase Diagrama 2.). A pesar de las fluctuaciones durante la crisis, donde la producción de vehículos bajó hasta las 70.000 unidades entre 2008 y 2009, la fábrica ha venido produciendo anualmente una media de entre 90.000 y 140.000 unidades. Emplea a unos 3.500 trabajadores de forma directa y a más de 10.000 de forma indirecta en toda la CAPV (EFE 20/05/14).

${ }^{8}$ El trabajo de campo realizado para la tesis doctoral, del cual el presente artículo es parte, suma un total de más de noventa entrevistas en profundidad a representantes sindicales de los cinco sindicatos citados, así como de representantes institucionales y patronales en la CAPV así como en la provincia de Barcelona. 
Diagrama 2.

Fragmentación de la Cadena de Valor de Mercedes-Benz Vitoria-Gasteiz: Porcentaje de Valor Ańadido Sobre Vehículo Producido

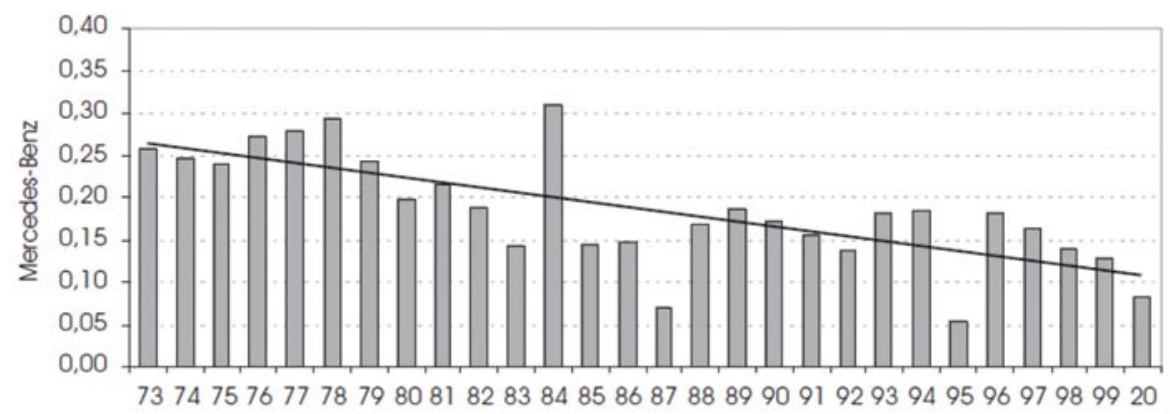

Fuente: Peligros y Bilbao-Ubillos, 2005: 92

La posición ventajosa que la planta ha tenido dentro del grupo Daimler-Europa a la hora de obtener inversiones de capital fijo ha sido promocionada por el gerente de la planta («Titos») como el resultado del esfuerzo de la empresa por innovar en nuevos procesos productivos y diseño de vehículos, así como por parte de aquellas organizaciones sindicales que "han apostado por el compromiso" y han ayudado a contener los costes laborales para obtener mayor competitividad dentro del Grupo Daimler (El Economista 24/02/16). Dicho de otra forma, la fábrica de MBV ha gozado de una época de bonanza durante las últimos dos décadas debido a que parte de la representación sindical ha adoptado una serie de estrategias corporativistas que desempoderaban ideológicamente el comité de empresa. Como veremos seguidamente, en los diferentes convenios se han intercambiado inversiones/empleo y algunas mejoras contractuales (e.g. menor jornada y subidas salariales) que reproducían una situación ventajosa dentro del mercado laboral para una parte de la plantilla, a cambio de una mayor flexibilidad horaria, mayor intensidad del trabajo y una creciente fragmentación de los salarios a través de la firma de dobles-escalas-salariales. Es decir, las mejoras económicas de algunos trabajadores se intercambiaban por un creciente desempoderamiento sobre el control y organización del proceso productivo y una fragmentación de las condiciones económicas de los trabajadores.

\subsection{Los «Pactos de Competitividad» en Mercedes-Benz Vitoria-Gasteiz}

Las relaciones laborales en MBV han cambiado mucho desde las movilizaciones de 1987, cuando un grupo de trabajadores y algunos activistas de la ciudad realizaron una huelga de hambre de 32 días para denunciar el despido de varios trabajadores que se negaban a participar en la introducción de «técnicas de producción ligera» en la fábrica (El País 30/06/87). La radicalidad ideológica 
de los trabajadores y el comité de empresa fue reduciéndose progresivamente durante los 90 a medida que la CGV tomaba su forma. La empresa ganó el favor de los representantes sindicales más afines e introdujo trabajadores afiliados a los mismos, reduciendo la representatividad de aquellas estrategias de clase más beligerantes (LAB1; LAB2; véase Ipar Hegoa 2016: 77-78; con respecto a dinámicas similares en Navarra).

Entre 1999 y 2011 se firmaron cuatro convenios colectivos que intercambiaron sistemáticamente ciertas mejoras en algunas cláusulas del convenio por la reforma, a peor, de otras, asegurándose así la "competitividad» de la planta (Tabla 1.). El convenio colectivo dejó de ser una plataforma para la reivindicación de las mejoras de las condiciones laborales, y se convirtió en un intercambio de cartas para ver cuánto estaban dispuestos a dar cada una de las partes para proseguir con la relación contractual. Estas dinámicas se acentuaron a la vez que la dirección aumentaba su presión en cada negociación, realizando amenazas con la deslocalización de parte de la producción o la planta entera en cada una de las negociaciones (El País 18/02/99; Cinco Días 23/07/03; El País 06/06/07; El País 16/10/11).

Tabla 1

Convenios Colectivos en Mercedes-Benz Vitoria-Gasteiz 1999-2011

\begin{tabular}{|c|c|c|c|c|}
\hline & \multicolumn{4}{|c|}{ MBV Convenios Colectivos (1999-2011) } \\
\hline & Jornada Anual & Salarios & Flexibilidad & $\begin{array}{l}\text { Doble-Escala- } \\
\text { Salarial }\end{array}$ \\
\hline $\begin{array}{l}\text { Acuerdo } \\
\text { 1999-2002 } \\
\text { UGT-ELA-CCOO }\end{array}$ & $1752 \mathrm{~h}>1744 \mathrm{~h}$ & $\begin{array}{l}\mathrm{IPC}+0.5 \% \\
(1999-2000) \\
\& \mathrm{IPC}+1 \% \\
(2001-2002)\end{array}$ & $\begin{array}{l}12 \text { Sábados «Banco } \\
\text { de horas»+/- } 9 \text { Días } \\
\& 9 . .^{\circ} \text { Hora }\end{array}$ & Ninguna \\
\hline $\begin{array}{l}\text { Acuerdo } \\
\text { 2003-2006 } \\
\text { UGT-CCOO }\end{array}$ & $1736 \mathrm{~h}>1712 \mathrm{~h}$ & $\mathrm{IPC}+1 \%$ & $\begin{array}{l}20 \text { Sábados «Banco } \\
\text { de horas»+5 Días/-18 } \\
\text { Días \& } 9 .{ }^{\circ} \text { Hora }\end{array}$ & $\begin{array}{l}\text { Tres Niveles (6-18 } \\
\text { Meses) Dispersión } \\
\text { Salarial } 11 \%-18 \% \\
€ 1,728-€ 4,928\end{array}$ \\
\hline $\begin{array}{l}\text { Acuerdo } \\
2007-2010 \\
\text { UGT-CCOO }\end{array}$ & $1712 \mathrm{~h}$ & $\mathrm{IPC}+0.75 \%$ & $\begin{array}{l}20 \text { Sábados «Banco } \\
\text { de horas» +5 Días } \\
\text { /-18 Días (-25 Días } \\
\text { Mientras ERTEs) \& } \\
\text { 9. Hora }\end{array}$ & $\begin{array}{l}\text { Tres Niveles (6-18 } \\
\text { Meses) Dispersión } \\
\text { Salarial } 11 \%-18 \% \\
€ 2,044-€ 5,754\end{array}$ \\
\hline $\begin{array}{l}\text { Acuerdo } \\
\text { 2011-2015 } \\
\text { UGT-CCOO }\end{array}$ & $1712 \mathrm{~h}$ & $\begin{array}{l}2.5 \% \text { Fijo } \\
(2011-2014) \\
\& \text { IPC }+0.5 / 1 \\
\%(2015)\end{array}$ & $\begin{array}{l}20 \text { Sábados «Banco } \\
\text { de horas»+5 Días/-18 } \\
\text { Días \& } 9 .^{\circ} \text { Hora }\end{array}$ & $\begin{array}{l}\text { Cinco Niveles (5 } \\
\text { ańos) Dispersión } \\
\text { Salarial } 30 \%-32 \% \\
€ 5,320-€ 10,710\end{array}$ \\
\hline
\end{tabular}

Fuente: varios convenios colectivos y cálculos del autor. 
Las relaciones entre diferentes sindicatos se hicieron cada vez más tensas, instaurándose a partir de 2003 una clara división entre las posturas pactistas de UGT y CCOO y las más reivindicativas de ELA y LAB (El País 24/12/03; Europa Press 19/12/08; El Correo 15/09/11). La adopción de estrategias microcorporatistas por UGT y CCOO para asegurar la viabilidad de la planta fue constatada de manera explícita cuando ante la pregunta de qué tipo de estrategias adoptaría su sindicato en el futuro, un representante sindical respondió lo siguiente:

La estrategia [de UGT] es que durante los próximos ańos la fábrica de MBV no sea comparada con ninguna otra [fábrica] dentro del Grupo Daimler. Que cuando el momento de asignar vehículos llegue, que [la viabilidad de] la fábrica no sea cuestionada [por la dirección]. Que por nuestra parte, en términos de flexibilidad regulada, productividad o formación de los trabajadores, no seamos cuestionados jamás. En el momento que otras plantas se interpongan en nuestras negociaciones, tendremos un problema. Pero lo que nosotros [UGT] tenemos que intentar es que la producción vaya más allá del año 2024 [cuando las inversiones de ahora ya estén amortizadas], y tenemos que trabajar desde ya mismo (UGT1).

Sin ser tan explícitos, argumentos parecidos fueron espetados por representantes sindicales de $\mathrm{CCOO}$ que han forjado hasta hace bien poco una alianza con UGT en MBV (CCOO1; CCOO2) ${ }^{9}$. Por lo tanto, en MBV ha existido a partir de la mitad de los años 90 claramente una adopción del discurso empresarial debido a la creciente subordinación económica dentro del proceso productivo y el mercado laboral (cf. Sección 2.2.), desempoderando a los trabajadores de la fábrica ideológicamente para articular estrategias más beligerantes, a la vez que eran participes "de forma regulada y consensuada" de la fragmentación de las condiciones salariales dentro de la plantilla que recrudecía el economicismo de las actitudes de los trabajadores (UGT2). Muy diferente, un representante sindical de ELA explicó cuán peligrosa era adoptar una posición de acompañamiento con la empresa, ya que la lógica del capital viene a ser siempre la misma:

En ELA, como estrategia y política sindical, siempre argumentamos que si el I $+\mathrm{D}$ de una compañía es competir en precios, perderemos nuestra lucha [de clase] y los trabajadores estarán perdidos. Hay siempre alguien que puede producir más barato que tú. Siempre, siempre. [...] Y nosotros sabemos que la empresa siempre busca aquellos que venderán [su fuerza de trabajo] más barato. El problema en MBV es que siempre hay alguien dispuesto a venderse muy barato. Esto desactiva al resto de trabajadores que quieren pelear, porque la empresa ya sabe que algunos trabajadores aceptarán peores condiciones, y que son mayoría en el comité de empresa. Entonces... MBV no tiene nada que ofrecernos (ELA1).

9 Véase CCOO (04/05/16; 10/05/16); para una reflexión de la secretaría confederal de Euskadi sobre las alianzas en el Comité de Empresa de MBV. 
La captación de algunos representantes sindicales en MBV se contrapone a aquellos que no quieren agachar la cabeza tan rápido, a aquellos que prefieren «seguir dando unos pasos más allá para poder ver hasta dónde podemos realmente llegar» (LAB2). No es, sin embargo, en el comité de empresa de MBV donde podremos ver una estrategia beligerante contundente, sino en varias empresas proveedoras localizadas en la misma fábrica donde la adopción de una estrategia coordinada y de oposición por parte de ELA permitió mejorar sustancialmente las condiciones laborales de los/las trabajadores/as. Todo ello pese a tener una posición estructural más desventajosa que la de sus compañeros de MBV en la CGV.

\subsection{Los proveedores y subcontratas siguen su propio camino: ELA empodera a los trabajadores y mejora sus condiciones laborales}

A pesar de la relativa peor posición estratégica que los trabajadores de niveles inferiores en las CGV tienen, Beverly Silver (2003: 13-14) nos recuerda la importancia del poder sobre el control del proceso productivo en el centro de trabajo, es decir, sobre la capacidad que los trabajadores retienen para interrumpir el proceso de valorización del capital. Dentro de las CGV, y en especial dentro de la industria automovilística con la organización Just-in-Time y Just-in-Sequence, la posición de los proveedores TIER1 en las inmediaciones de la fábrica es crucial. Cualquier conflicto laboral que interrumpa el proceso productivo en una empresa TIER1 afectará cuasi-automáticamente a la empresa matriz. Existen algunos casos, como en la planta de ensamblaje de FIAT en el sur de Italia (Pulignano, 2005) u algunas factorías en Alemania (Dorigatti, 2013), donde dicha relación se ha asimilado y, luego, aprovechado por parte de los sindicatos para poder demandar mejores condiciones en las empresas proveedoras y subcontratadas. A lo largo del territorio Español, en cambio, estos casos no han sido documentados ${ }^{10} \mathrm{y}$, por consiguiente, están ausentes del imaginario colectivo. El caso de los trabajadores proveedores de MBV puede ser ejemplar.

Como el Diagrama 2. muestra más arriba, la CGV fue tomando forma desde los ańos 80, consolidándose a finales de los 90 y principios de los 2000 con la ampliación de la fábrica y la creación del I+PARK (El Correo 03/06/07). El I+PARK es una nave adjunta donde se ultiman las piezas y segmentos del coche que más tarde se trasladan a través de railes o carretillas a la línea de montaje. Sumando el I+PARK y los trabajadores subcontratados a lo largo de la fábrica los representantes sindicales calculan que hay alrededor de otros 1.000 trabajadores. Las condiciones laborales con las que fueron contratados a finales de los 90 y principios de los 2000 eran las del Convenio Colectivo Provincial del Metal de Álava; mientras UGT obtuvo la mayoría en las primeras elecciones sindicales (UGT3; ELA3).

10 Véase por ejemplo: Recio et al. (2008); Banyuls y Lorente (2010). 
El poder de asociación y organizativo entre los trabajadores del I+PARK era mínimo, ya que existía (y existe) muy poca o ninguna coordinación entre el comité de empresa de MBV y los diferentes delegados sindicales de las empresas proveedoras (UGT1; UGT2; UGT3; UGT4; UGT5). A su vez, el poder económico de los nuevos trabajadores, tanto en el mercado laboral como en el proceso productivo, eran relativamente pequeńos: los puestos de trabajo requerían una escasa cualificación a la vez que había altas tasas de empleo femenino (UGT3; ELA3). Esto se materializó en posiciones sindicales más conformistas que combativas. Hasta entonces, la estrategia de MBV había sido exitosa ya que, con el beneplácito de UGT que había conseguido un número alto de contrataciones/ afiliaciones en las empresas del I+PARK, habían conseguido reducir los costes laborales sustancialmente en comparación a los trabajadores que tenían el «mono de MBV». La tendencia pues era que los salarios y condiciones de los trabajadores del I+PARK estuvieran reguladas por el convenio sectorial provincial, devaluándose entre un 25-35\% en relación a los de MBV, y pareciéndose al resto de fábricas de ensamblaje de automóviles en el Estado (véase Alaez, Ricardo. et al. 2009).

En las empresas TIER1 más grandes dentro de MBV (ANSA-Faurecia; SAS, HBPO, Antolín y DHL-EXEL), la transformación que ELA experimentó históricamente hacia posiciones más beligerantes durante los 90 ganó momento (Elorrieta, 2013; Dufour, Christian y Hege, Adelheid. 2009). Después de uno o dos años de escasa actividad sindical, varios representantes sindicales de ELA en las fábricas, y con el apoyo de la federación del metal, subvirtieron la tendencia pactista y propicia a esperar a que las negociaciones sectoriales fueran las que regularan sus condiciones:

Lo primero que intentamos fue organizar los comités de empresa, re-lanzar las elecciones sindicales y, de ahí en adelante y siempre en paralelo, generar la necesidad y lazos entre los trabajadores para fortalecer la afiliación sindical. Así los trabajadores serían conscientes de que a través de la negociación colectiva a nivel de empresa podían mejorar sus condiciones sustancialmente (ELA1).

La estrategia organizativa tuvo sus efectos positivos, y los delegados de ELA lograron rápidamente convencer a los trabajadores no sindicados e incluso a muchos de los sindicados a UGT para que se afiliaran a ELA, llegando a una afiliación de entre el 70-80 \% de los trabajadores del I+PARK (UGT3; UGT4). A su vez, mejoras sustanciales fueron conseguidas a través de, primero, pactos de empresa y, posteriormente, convenios de empresa, que materializaban una mayor beligerancia en la negociación colectiva en el centro de trabajo ${ }^{11}$. O dicho de otra forma, los trabajadores y delegados sindicales empoderaron sus estrategias de

11 Por ejemplo, en un año los trabajadores de ANSA-Faurecia consiguieron una subida salarial del $12.7 \%$, llegando al $44 \%$ en menos de tres años (Astekaria, 2001: 4). 
clase a través de la articulación de discursos más combativos que ampliaban y subvertían la lógica economicista y pactista existente hasta entonces. Según los propios delegados de UGT en algunas de las empresas TIER1 en MBV (UGT3; UGT4; UGT5), los delegados de ELA mantuvieron una posición más combativa durante las negociaciones de los años 2000 que les permitió conseguir aumentos salariales y mejoras en las condiciones laborales:

(Entrevistador: ¿Y difiere la estrategia de UGT de la de ELA?)

Diría que quizás a nosotros, tanto a mí como a UGT, nos gusta agotar el diálogo. Tampoco digo que ELA no dialogue, eh. Pero nosotros como estrategia [sindical] es apurar el diálogo con la empresa [...]. Si te soy sincero creo que presionamos menos, y quizás sea por eso por lo que nos va peor [en la representatividad sindical en el I+PARK]. Porque yo no soy gente de presionar [en las negociaciones]. Y si hay huelga o manifestación mando una nota informativa y cada uno sabrá lo que tiene que hacer. Entonces... desde mi punto de vista, sí creo que ELA presiona un poquito más o mete más fuerza. Y ahí es quizás [donde radique] parte de su éxito, pero como yo no pienso que se tengan que conseguir las cosas así... Pero he de reconocer que han firmado buenos convenios".

(Entrevistador: ¿Y si la negociación la hubierais liderado vosotros, creéis que hubierais conseguido esos convenios?)

[Silencio]. Pues igual no. [Silencio].

(Entrevistador: ¿Crees que hubierais apostado por posiciones más conservadoras?)

Pues quizás la gente se hubiera coartado más a la hora de pelear. Quizás por la forma de ser de unos y de otros. ¿Sabes lo que te quiero decir? (UGT3).

A pesar de la mayor conflictividad que los delegados de ELA quisieran articular y proyectar al conjunto de los trabajadores para que estos se asociaran y organizaran en la lucha por unas mejores condiciones, la posición estructural en la CGV también les permitió negociar y mejorar las condiciones de trabajo sin tener que realizar prácticamente ningún tipo de huelga o acción colectiva. En vez de «materializar» su poder sobre el control del proceso productivo les bastó sólo con «mostrarlo»:

Te diría que en todos estos años que el I+PARK ha existido, quizás no hayamos hecho ninguna huelga para parar la línea de montaje. Bueno, igual una vez o dos veinte minutos o media hora, pero algo ridículo. Nuestra estrategia en las empresas no ha sido de chantaje: o nos das esto o te paramos MBV.

(Entrevistador: ¿Porque parar MBV sería una acción peligrosa?)

No, no por eso. En ELA decimos que tan importante es la capacidad de confrontar como la confrontación en sí misma. [...] En un contexto donde las empresas no nos tiran demasiado de la cuerda tampoco estamos interesados en hacerlo. Vamos a llevarnos bien y no nos hagamos dańo el uno al otro. [...] Frecuentemente, las batallas no toman lugar porque existe un respeto mutuo entre los adversarios, y esa es la idea. Nuestro objetivo como sindicato no es confrontar por el hecho de confrontar, el objetivo es que nuestro adversario sepa que tenemos la capacidad de confrontar para poder llegar a un acuerdo. Y si no llegamos a un acuerdo, confrontaremos o no, 
pero sé que puedo confrontar y luego decidiré. Ese es el dilema actual en la correlación de fuerzas [entre clases].

(Entrevistador: ¿Y no piensas que si peleáis demasiado las empresas no ganarán lo suficiente?)

En ELA pensamos que las empresas se irán cuando ellas decidan irse. Todavía creemos que las empresas [del I+PARK] tienen un gran margen de beneficios y nadie nos ha demostrado lo contrario. Estaríamos contentos de que alguna de las empresas proveedoras nos enseńara una cuenta de resultados deficitaria. Eso no existe, siempre ganan dinero. MBV es la gallina de los huevos de oro, y si no lo fuera ya se hubieran ido de allí [ríe]. [...] Te digo que durante algunas de las negociaciones, algún director de RRHH me dijo: «Te daré un IPC+2 o un IPC+4, pero sólo si me traes otro convenio firmado por otro proveedor». Ves, el problema no es darnos más dinero, el problema es que no quieren dar la impresión al resto de que pueden darnos el dinero. (ELA1).

La renovación sindical o empoderamiento de los trabajadores no fue únicamente resultado de la radicalización de los trabajadores a través de la negociación liderada por ELA. La mejor coordinación entre los diferentes comités de empresa, la asistencia técnica del Gabinete Económico y de Negociación Colectiva y una caja de resistencia confederal que incrementaba la capacidad de confrontar en caso de un bloqueo en las negociaciones fueron factores determinantes también (Dufour y Hege, 2009; Elorrieta 2013). Los delegados sindicales de ELA en las diferentes empresas del I+PARK han mantenido un estrecho contacto desde la ampliación de la fábrica a principios de los 2000, teniendo reuniones regulares y coordinando los procesos de negociación colectiva de forma conjunta (ELA2; ELA3; ELA4). Durante las negociaciones, los representantes sindicales intentaban tapar las flaquezas de algunos comités y reforzar las posturas de donde tuvieran más fuerza (ELA1). En su conjunto, los trabajadores de los proveedores y subcontratas más grandes cobran alrededor de un 15-25\% menos (5.000-7000 €) que los trabajadores antiguos en MBV y un $40 \%$ más (7000 €) que el Convenio Provincial del Metal de Álava. A su vez, la mayoría tienen la misma jornada anual que MBV y menor flexibilidad horaria.

Antes de concluir, sería importante hacer presente que las mejores condiciones conseguidas por el conjunto de trabajadores en el I+PARK son únicamente de carácter provisional y que, debido a su posición subordinada en la CGV de $\mathrm{MBV}$, están siempre sujetas a las amenazas del capital de perder el contrato en la subasta por el producto en favor de otra empresa "más competitiva» y con menores costes laborales o, simplemente, deslocalizarse a otro ámbito geográfico. Crucialmente, después de la crisis, y a raíz del Convenio Colectivo de MBV firmado en 2011 (véase Tabla 1), la ampliada doble-escala-salarial en MBV ha puesto en entredicho los salarios de los trabajadores del I+PARK. Siendo los salarios iguales para la mayor parte de los trabajadores de los proveedores/subcontratas (alrededor de 26.000-27.000 € brutos anuales), mientras que los de un trabajador recien incorporado en MBV son de unos 20.000-22.000€: 
La dependencia que tenemos los proveedores con respecto a MBV es tal que, ahora que MBV ha ampliado su doble-escala-salarial, nuestros nuevos contratos tienen mejores condiciones que los suyos. Por defecto, y en teoría, si queremos subsistir como empresa dentro de MBV, nos están forzando a empeorar nuestras condiciones para poder competir [con sus salarios]. [...] Porque si contratan a 400 trabajadores en MBV con menores salarios que tú, MBV va argumentar que por qué nosotros cobramos más que sus propios trabajadores. [...] Luego viene nuestra empresa y nos dice: "ahí afuera hay otra empresa donde me cobran $17.000 €$, y si les digo que trabajen cinco horas, trabajan cinco horas, y si les digo diez trabajan diez, y esta gente me trabaja igual que tú». Para que veas que estamos constantemente bajo una amenaza continua. Hacernos respetar luchando es lo único que nos queda, y no tendríamos que dejarnos intimidar, pero, aquí tampoco hay ningún héroe y el coraje es relativo... y nuestras piernas también tiemblan cuando negociamos, pero tenemos que resistir y seguir adelante (ELA3).

La naturaleza contradictoria y, por lo tanto, provisional de las victorias sindicales de ELA en MBV queda manifiesta ante los continuos cambios productivos y organizativos a lo largo de la CGV, por no hablar de las importante transformaciones dentro del marco regulatorio del mercado de trabajo y la estructura de la negociación colectiva. Todo ello nos conduce a concluir que el poder y estrategias de clase están en continua transformación y que, mediante la dialéctica entre estructura y agencia (Sección 2.1.), podemos estudiar los límites y posibilidades de la lucha de clases dentro de un contexto dado. La oposición cada vez más contundente por parte de empresas y patronal a la hora de conceder mejoras en las condiciones laborales tanto en la CAPV, como en el resto del Estado español o Europa, empuja a los diferentes actores sociales a reflexionar y articular nuevas estrategias para empoderarse como clase y así establecer una serie de límites, si no mejoras o cambios estructurales, en las condiciones de los trabajadores y ciudadanos a lo largo del mundo. Aunque el capital esté en una posición superior a la hora de negociar, el caso de estudio en el I+PARK de Mercedes-Benz Vitoria-Gasteiz nos recuerda que hay márgenes de lucha, por muy provisionales que puedan ser. Es decir, a pesar de la tendencia general de desempoderamiento que la clase trabajadora ha experimentado desde los ańos ochenta (Sección 2.2.), debido a la naturaleza abierta y desigual del capitalismo, existen contextos donde los trabajadores pueden luchar y ganar. El juego, por lo tanto, sigue abierto. ¿Cuál será el siguiente movimiento acertado para mejorar nuestra posición estratégica? Esa es la pregunta que habrá que hacerse antes mejor que tarde.

\section{Conclusión}

Este artículo ha presentado un marco teórico para poder entender y analizar, desde un punto de vista Marxista y sistémico, las estrategias sindicales en 
las Cadenas Globales de Valor. A un nivel general de abstracción, el artículo ha teorizado inicialmente sobre la interacción entre estructura y agencia, presentando seguidamente una definición de poder y estrategias de clase (Sección 2.1.). El artículo ha revisado la literatura para situar dicho esquema en un contexto de lucha sindical dentro de las Cadenas Globales de Valor (Sección 2.2.). La Sección 3. ha presentado la pregunta de investigación en su forma más amplia, así como el método usado para realizar el estudio de caso. La Sección 4. ha presentado en dos partes las estrategias sindicales dentro de Mercedes-Benz y los proveedores/subcontratas TIER1 situados en la fábrica. Al contrario de lo que sugiere la literatura académica sobre las condiciones laborales en las empresas TIER1, el caso presentado en este artículo explica cómo las estrategias de empoderamiento a nivel de empresa del sindicato ELA fueron (relativamente) exitosas. De esta forma, el artículo presenta una experiencia positiva donde los trabajadores bajo el lema united we stand pudieron mejorar su posición estructural en unos tiempos donde la tendencia era más bien la contraria, i.e. divided we fall. La conclusión es, por lo tanto, que las estrategias sindicales beligerantes e inclusivas ante las demandas empresariales pueden incidir de forma positiva, aunque provisional, sobre el poder de clase de los trabajadores en un contexto donde la tendencia es la contraria. Existen márgenes de lucha y tenemos que repensarlos.

\section{Entrevistas}

ELA1 (24/02/15) Representante de Federación del Metal de Álava

ELA2 (26/03/15) Delegado sindical en MBV

ELA3 (26/03/15) Delegado sindical en I+PARK

ELA4 (26/03/15) Delegado sindical en I+PARK

UGT1 (10/04/15) Delegado sindical en MBV

UGT2 (10/04/15) Delegado sindical en MBV

UGT3 (17/04/15) Delegado sindical en I+PARK

UGT4 (04/03/15) Delegado sindical en I+PARK

UGT5 (04/03/15) Delegado sindical en I+PARK

LAB1 $(30 / 03 / 15)$ Delegado sindical en MBV

LAB2 (30/03/15) Delegado sindical en MBV

CCOO1 (11/03/15) Delegado sindical en MBV

CCOO2 (11/03/15) Representante de Federación del Metal de Álava

\section{Hemeroteca}

Astekaria (02/03/01) «Jovenes Luchan y Ganan: Luis Fernández, Tras la Firma del Pacto de ANSA de Vitoria».

Cinco Días (23/07/03) «Mercedes amenaza con llevarse producción de Vitoria a Berlín» http://cincodias.com/cincodias/2003/07/23/empresas/1058967586_850215.html 
CCOO (04/05/16) «El sindicato "no se ha deslizado a ningún frente del no en Mercedes", sigue apostando por "la negociación y el convenio"” http://www.industria.ccoo.es/ noticia: $149897--$

CCOO (10/05/16) «Resolución de la Comisión Ejecutiva de CCOO de Euskadi sobre lo acontecido en Mercedes» http://www.ccoo-euskadi.net/webeuskadi/ Informacion:Noticias:995642--

EFE (20/05/14) «Vitoria fabricará la Clase V para todo el mundo» http://www.elcorreo. com/alava/economia/201405/20/vitoria-fabricara-clase-para-20140520163357.html

Europa Press (19/12/08) «Mercedes Volvera a reunirse con el Comité al no avanzar negociación del ERE» http://www.europapress.es/economia/noticia-economia-motormercedes-benz-vitoria-volvera-reunirse-enero-comite-no-avanzar-negociacion-ere20081219182637.html

El Correo (15/09/11) «ELA, LAB, ESK y CGT denuncian ante la Inspección de Trabajo a Mercedes» http://www.elcorreo.com/alava/20110915/economia/denuncian-anteinspeccion-trabajo-201109151354.html

El Correo (03/06/07) «Si Mercedes se marcha de Vitoria, iríamos tras ella» http://www. elcorreo.com/vizcaya/prensa/20070603/economia_viz/mercedes-marcha-vitoriairiamos_20070603.html

El Economista (24/02/16) «Mercedes Vitoria está de récord, pero cuesta encontrar personal cualificado»http://www.eleconomista.es/ecomotor/motor/noticias/7373867/02/16/ Mercedes-Vitoria-esta-de-record-pero-cuesta-encontrar-personal-cualificado.html

El País (30/06/87) «Despedidos de Mercedes-Benz acuden al juicio en camilla» http://elpais.com/diario/1987/06/30/economia/552002416_850215.html

El País (18/02/99) «Mercedes-Benz elige Vitoria para invertir 601 millones de euros en una nueva furgoneta» http://elpais.com/diario/1999/02/18/economia/919292401_850215.html

El País (06/06/07) «La plantilla de Mercedes rechaza el nuevo convenio en un referéndum» http://elpais.com/diario/2007/06/06/paisvasco/1181158808_850215.html

El País (16/10/11) «"Queremos cogestión, no bloqueo social» http://elpais.com/ diario/2011/10/16/negocio/1318770207_850215.html

El País $(24 / 12 / 03)$ «UGT y CC OO firman el convenio de eficacia limitada en Mercedes y esperan la adhesión de los 4.200 trabajadores» http://elpais.com/diario/2003/12/24/ paisvasco/1072298402_850215.html

\section{Bibliografía}

Alaez, Ricardo y Beneto-Carmona, Maite (2008): «Evaluating the Risk of Plant Closure», European Planning Studies, 16 (1), pp. 61-80.

Alaez, Ricardo; Bilbao-Ubillos, Javier; Beldarrain, V. C., y García, J. C. L. (2009): «Reflexiones sobre la Crisis de la Industria Española del Automóvil y sus Perspectivas», Información Comercial Española, ICE: Revista de economía, (850), pp. 41-56

Antentas, Josep Maria (2015): «Sliding scale of spaces and dilemmas of internationalism», Antipode, 47(5), pp. 1101-1120.

Auñamendi Entziklopedia (2008): «Mercedes-Benz España, Factoría de Vitoria», http:// www.euskomedia.org/aunamendi/95305

Banyuls, Josep María y Lorente, Raúl (2010): «La industria del automóvil en España: Globalización y gestión laboral», Revista de economía crítica, (9), pp. 31-52. 
Bilbao-Ubillos, Javier (2010): «The Spatial Variable in the Recent Configuration of the Value Chain in the European Automotive Industry", Tijdschrift voor economische en sociale geografie, 101(3), pp. 357-363.

Boundi, Fahd y Flores, Gabriel (2014): «Crisis y Encrucijada de la Industria de Componentes de Automoción», Fundación 1.0 de Mayo, Número 87.

Boyer, Robert (1990): The regulation school: a critical introduction. US: Columbia University Press.

Brenner, N. (2004): New State Spaces. Cambridge: Oxford University Press.

Buendía, Luis y Las Heras, Jon (2014): «Disentangling Welfare State Reforms During the Crisis», Taller Rights and Economic Crisis in Spain and Europe, SPERI, Universidad Pompeu Fabra.

CAPRILE, Maria (2000): «Outsourcing and industrial relations in motor manufacturing», European Foundation for the Improvement of Living and Working Conditions, EIRO.

Castillo, Juan-Jose y Lopez-Calle, Pablo (2003): Los Obreros del Polo: Una Cadena de Montaje en el Territorio, Editorial Complutense, Madrid.

Contractor, Farok, Kumar, V., Kundu, S. K., y Pedersen, T (2010): «Reconceptualizing the firm in a world of outsourcing and offshoring: The organizational and geographical relocation of high-value company functions", Journal of Management Studies, 47(8), pp. 1417-1433

Cumbers, A., Nativel, C., y Routledge, P. (2008): «Labour agency and union positionalities in global production networks», Journal of Economic Geography, 8(3), 369-387

Devine, Fiona (2002): "Qualitative methods», en Theory and methods in political science, David Marsh y Gary Stoker (eds.), pp. 197-215.

Dorigatti, Lisa (2013): Defending the Core, Tésis Doctoral, Universita Degli Studi di Milano.

Dufour, Christian y Hege, Adheleid (2009): «12e congrès de ELA, confédération syndicale basque", Chronique internationale de l'IRES, 117, pp. 27-36.

DunN, B. (2004): Global restructuring and the power of labour, London: Palgrave Macmillan.

Elorrieta, Joxe (2013): Sindicalismo combativo (ELA 2012: crecer desde el contrapoder), Lan Harremanak. Revista de Relaciones Laborales, núm. 27.

ERNE, R. (2008): European unions: labour's quest for a transnational democracy. US: Cornell University Press.

Gerefri, Gary (2014): «Global value chains in a post-Washington Consensus world», Review of International Political Economy. 21(1), 9-37.

Gracia, Manuel y Paz, María José (2014): «Industria del automóvil española: valoración de su patrón de inserción externa desde un enfoque de cadenas globales de producción", Jornadas de Economía Critica XIV, Universidad de Valladolid, 4 y 5 de Septiembre.

Gumbrell-McCormick, Rebecca y Hyman, Richard (2013): Trade unions in western Europe: Hard times, hard choices, Oxford University Press.

Harvey, David (2014): Seventeen contradictions and the end of capitalism. Oxford University Press (UK).

Hyman, Richard (1975): Industrial Relations: A Marxist Introduction, Basingstoke: Macmillan

- (1989): The political economy of industrial relations: Theory and practice in a cold climate, London: Palgrave MacMillan

- (2007): «How can trade unions act strategically?», Transfer: European Review of Labour and Research, 13(2), 193-210. 
Ipar Hegoa (2016): «Botere Sindikala: errealitate aldakorra», Ikusmiran, Uztaila.

Jessop, Bob (1990): State theory: putting the capitalist state in its place, Cambridge: Polity Press.

- (2008): State Power. Cambridge: Polity Press.

- (2013): «Revisiting the regulation approach: Critical reflections on the contradictions, dilemmas, fixes and crisis dynamics of growth regimes", Capital \& Class, 37(1), pp. 5-24.

- (2016): The State: Past, Present, Future. Cambridge: Polity Press.

Jódar, Pere, Vidal, Segi, y Alós, Ramon (2011): «Union activism in an inclusive system of industrial relations: Evidence from a Spanish case study», British Journal of Industrial Relations, 49(1), pp. 158-180

Kalecki, Michael (1943): «Political Aspects of Full employment», The Political Quarterly, $14(4), 322-330$.

- (1954): Theory of Economic Dynamics, Monthly Review.

Kelly, John (1998): Rethinking Industrial Relations: Mobilization, Collectivism, and Long Waves, UK, Psychology Press.

Kotz, David (2013): «The current economic crisis in the United States: A crisis of overinvestment", Review of Radical Political Economics, Vol. 45 (3): pp. 284-294.

Kotz, David, McDonough, Terrence y Reich, Michael (1994): Social structures of accumulation: The political economy of growth and crisis, Cambridge, Cambridge University Press.

Kvale, Steinar, y Brinkmann, Svein. (2009). Interviews: Learning the craft of qualitative research interviewing. UK: Sage

Las Heras, Jon (2015): "Framing Labour Strategies in Global Value Chains: Any Inflexion Point Ahoy?», Wirtschaft und Management, Vol. 22, August.

Marsh, David y Stoker, Gary (2002): Theory and methods in political science, London: Palgrave-Macmillan.

McDonough, Terrence, Reich, Michael, and Kotz, David (2010): Contemporary capitalism and its crises: Social structure of accumulation theory for the 21st century, Cambridge: Cambridge University Press.

Moody, Kim (1997): Workers in a lean world: Unions in the international economy, London: Verso Books.

LÉvesque, Christian and Murray, Gregor (2010): «Understanding union power: resources and capabilities for renewing union capacity», Transfer: European Review of Labour and Research, 16(3), pp. 333-350.

Nieto, Fernando (2009): «Problemática de la estructura de la negociación colectiva en España», Temas laborales: Revista andaluza de trabajo y bienestar social, (100), pp. 629661.

O'Hara, Athony Phillip (2006): Growth and development in the global political economy. London and New York: Routledge.

Ortiz-Villajos, Jose María (2010): «Aproximación a la historia de la industria de equipos y componentes de automoción en España», Investigaciones de historia económica, 6 (16), pp. 135-172.

Otaegui, Amaia (2014): «Desequilibrio negocial y debilitamiento del actor sindical como efectos de la reforma laboral», Cuadernos de Relaciones Laborales, 32(2), pp. 337-360.

Panitch, Leo (1981): «Trade unions and the capitalist state», New Left Review, 125 (1), pp. 21-43. 
Peligros, Carmen y Bilbao-Ubillos, Javier (2005): «El proceso de externalización productiva en la industria española del automóvil», Economía industrial, (358), 87-98.

Pulignano, Valeria (2005): «Union responses to "multi-enterprise” factories in the Italian motor industry", Industrial Relations Journal, 36(2), 157-173.

Pulignano, Valeria; Stewart, Paul; Danford, A., y Richardson, M. (2008): Introduction "Flexibility" at Work: Critical Developments in the International Automobile Industry. UK: Palgrave-Macmillan

Recio, Albert; Banyuls, Josep; Cano, E.; Lorente, Raul, y Amigo, M. (2008): "The Motor Industry in Spain», en Caputo, Paola y Delle Corte, Elisabetta (ed.) The labour impacto of Globalization in the Automotive Industry. A comparison of the Italian, German, Spanish and Hungarian Motor Industries, Quaderni della Fondazione G. Bradolini n. ${ }^{\circ}$ 45, pp. 153-216.

Rehmann, Jan (2013): Theories of ideology: The powers of alienation and subjection. Belgium: Brill.

SAyer, Andrew (2010): Method in Social Science: Revised 2nd Edition. London: Routledge.

Schulten, Thorsten (2013): «Current Trends in Collectively Agreed Wages and Wage Drift in Europe 2001-2010», WSI Working Paper, Dusseldorf, February.

SELwyN, Benjamin (2012): «Beyond firm-centrism: Re-integrating labour and capitalism into global commodity chain analysis", Journal of Economic Geography, 12(2), pp. 205-26.

SILver, Beverly (2003): Forces of labor: workers' movements and globalization since 1870, Cambridge: Cambridge University Press.

Sturgeon, Timothy, Van Biesebroeck, Johannes and Gereffi, Gary (2008): «Value Chains, Networks and Clusters: Reframing the Global Automotive Industry», Journal of Economic Geography, 8 (3), pp. 297-321.

URBAN, Hans-Jurgen (2012): Crisis corporatism and trade union revitalisation in Europe. In S. Lendhorff (Ed.) A triumph of failed ideas European models of capitalism in the crisis, Vol 219. Brussels: ETUI.

VALDES DAL-RÉ, Fernando (2012): La negociación colectiva, entre tradición y renovación, Comares, Granada.

Waddington, Jeremy (2011): European Works Councils and Industrial Relations: A Transnational Industrial Relations Institution in the Making. London: Routledge.

ZaGelmeYer, S. (2001): "Getting in gear for global competition: pacts on employment and competitiveness in the EU automobile industry", Transfer: European Review of Labour and Research, 7(4), pp. 650-656. 